\title{
Simultaneous defense against shell entry and shell crushing in a snail faced with the predatory shorecrab Carcinus maenas
}

\author{
Timothy C. Edgell ${ }^{1,4}{ }^{4}$, Christian Brazeau ${ }^{2}$, John W. Grahame ${ }^{3}$, Rémy Rochette ${ }^{1}$ \\ ${ }^{1}$ Department of Biology, University of New Brunswick, Saint John, New Brunswick E2L 4L5, Canada \\ ${ }^{2}$ Department of Biology, McGill University, Montréal, Québec H3A 1B1, Canada \\ ${ }^{3}$ Institute of Integrative \& Comparative Biology, University of Leeds, Leeds LS2 9JT, UK \\ ${ }^{4}$ Bamfield Marine Sciences Centre, Bamfield, British Columbia V0R 1B0, Canada
}

\begin{abstract}
Prey with versatile predators need diverse defenses. Such an example of a versatile predator is the voracious European green crab Carcinus maenas. Green crabs prey on snails by either crushing shells or, when shells are too tough to break, by extracting flesh through the shell opening (aperture). Among populations in the northwest Atlantic, the claw size of green crabs (an indicator of crushing strength) co-varies with shell mass of the intertidal snail Littorina obtusata (mass is an indicator of a shell's crushing resistance); thus shell-crushing predation appears to be an important part of the predator-prey interaction. We report that aperture occlusion and soft tissue withdrawal depth (two shell-entry defenses) of L. obtusata snails co-vary with their shell mass (an anti-crushing trait) among populations. When snails were fed directly to green crabs in the laboratory, populations with smaller shell openings and deeper withdrawal depths were less frequently killed by shell-entry attacks, and these same populations, with more massive shells, were also better at resisting shellcrushing attacks. Results provide compelling evidence that greater shell mass, a smaller shell opening, and deeper withdrawal depth are adaptive traits for snails faced with green crab predators. Furthermore, results suggest that American L. obtusata responded to the introduction of green crabs by escalating both anti-crushing and anti-entry defenses.
\end{abstract}

KEY WORDS: Predator-prey · Invasive species - Biogeography · Functional morphology · Adaptation · Rocky intertidal

Resale or republication not permitted without written consent of the publisher

\section{INTRODUCTION}

Stereotypical traits in prey (e.g. flight responses, armour, camouflage) can reveal important selection pressures that have driven their evolution, and indirectly offer insights into the habits of their dominant predators. For example, marine and freshwater mollusks often have highly sculptured shells (e.g. spires, tubercules, apertural teeth, elevated thickness) that reflect adaptation to shell-swallowing, shell-crushing, or shell-entering predation by fish, crabs and a variety of other predators (Vermeij 1987). Although widespread, such examples of anti-molluscivore adaptation derive disproportionately from studies involving a single type of predator (e.g. shell crushers, lip peelers). Less understood is how prey respond to multiple and simultaneous selection pressures that target different kinds of defenses. In nature, such predator complexity (e.g. when prey have either single or multiple predators that exhibit diversified attack strategies) can make it difficult to predict trajectories of prey adaptation. When predation is complex, the possible adaptive pathways for prey include responding to either (1) the single most dominant selection pressure, or (2) multiple selection pressures simultaneously (DeWitt et al. 2000, DeWitt \& Langerhans 2003). We investigate the interac- 
tion between the predatory European green crab Carcinus maenas and the intertidal snail Littorina obtusata. The interaction between green crabs and their gastropod prey offers an invaluable opportunity to study how prey respond to multiple selective pressures because green crabs are renowned for being voracious predators capable of diversified attack behaviours (Elner \& Hughes 1978, Cunningham \& Hughes 1984, Johannesson 1986, Rochette et al. 2007).

Following the green crab's introduction to North America in the 19th century, its newly formed interaction with Littorina obtusata led to a rapid and adaptive escalation in this snail's shell strength (Vermeij 1982, Seeley 1986, Trussell 1996, Trussell \& Smith 2000), indicative of the importance of shell-crushing in this predator-prey dynamic. Moreover, green crab claw size (an indicator of crushing strength) and L. obtusata shell mass (an indicator of crushing resistance) currently co-vary among populations in the Gulf of Maine and the southern Bay of Fundy (Edgell \& Rochette 2007, 2008), further evidence that crushing is indeed an important mode of attack for green crabs and, consequently, L. obtusata. However, green crabs are not specialist shell-crushers. This predator will attack snails via shell entry (the extraction of snails from through the shell opening whilst leaving shells unscathed) as often, and sometimes more often, as shell crushing when shells appear too tough to break (Rochette et al. 2007). Concurrent shell-crushing and shell-entry predation by green crabs on wild snail populations has been documented in the Bay of Fundy, Canada (Edgell \& Rochette 2008), north and south Gulf of Maine, USA (Hadlock 1980, Rochette et al. 2007), Ireland (Ebling et al. 1964), and Sweden (Johannesson 1986), suggesting that this duality of predation behaviours is widespread. In the Gulf of Maine, L. obtusata snails may have therefore responded to both shellcrushing and shell-entry predation upon green crab introduction; however, this intriguing possibility has not been studied.

We addressed this problem by asking if variation in anti-crushing traits (shell mass) correlates to variation in anti-entry traits (aperture occlusion and soft tissue withdrawal depth) among natural populations of Littorina obtusata in the northwest Atlantic. If snails have indeed responded to both modes of predation, we should expect that those living where green crab predation is intense would have both highly developed anti-crushing and anti-entry traits, whereas in areas where green crab predation is less intense, both kinds of defense should be less developed. We then tested the functional significance of putative among-shore differences in anti-crushing and anti-entry traits by feeding $L$. obtusata snails directly to green crabs in the lab.

\section{MATERIALS AND METHODS}

Measurements. Littorina obtusata shell breadth $(\mathrm{mm})$, measured as the maximum linear dimension perpendicular to the axis of coiling, was used as a metric of overall size. Shell mass (an indicator of shell strength or crushing resistance; Lowell et al. 1994) was measured to the nearest $0.001 \mathrm{~g}$ on an analytical balance, after separating shell from tissue and drying the shell in an oven at $60^{\circ} \mathrm{C}$ for $48 \mathrm{~h}$. Aperture area $\left(\mathrm{mm}^{2}\right)$ was measured by first digitizing shells in a standardized position - aperture plane parallel to the plane of the mounting stage - then tracing the inner edge of the apertural lip with OpenLab ${ }^{\circledR}$ image analysis software. Soft-tissue withdrawal depth was quantified in 2 ways following Edgell \& Rochette (2008). First, snails were prodded repeatedly with forceps to simulate a shell-entering crab attack, then, when snail tissue stopped withdrawing deeper into the shell, we measured (1) the linear distance of withdrawal from the shell lip to the snail's closest position to the aperture plane (referred to hereafter as 'retraction'; Fig. 1a); and
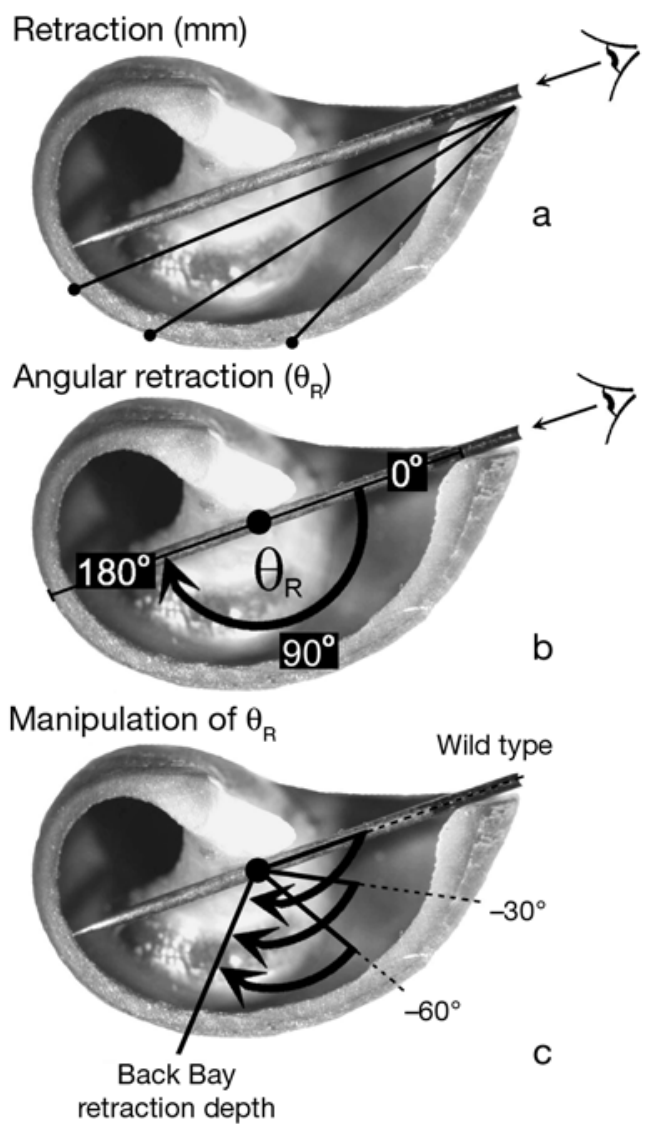

Fig. 1. Littorina obtusata. (a) Retraction, (b) angular retraction and (c) the kind of modification made to Back Bay shells to manipulate withdrawal depths for the predation experiment (Back Bay wild and 2 manipulated populations had similar shell breadths after modification) 
(2) the angular distance of retraction from the aperture plane, relative to the trajectory of maximum straight-line shell penetration, or line of sight into the shell (referred to hereafter as 'angular retraction' or ' $\theta_{\mathrm{R}}$ '; Fig. $1 \mathrm{~b}$ ).

Geography of antipredation traits. To determine if populations with highly developed anti-crushing traits (more massive shells) also had highly developed anti-entry traits, we tested for population-level correlations between (1) mass and aperture area, (2) mass and retraction, and (3) mass and angular retraction, among 12 geographically separated sites in the Gulf of Maine and the southern Bay of Fundy (Table 1, Fig. 2). All sites were rocky intertidal, dominated by the macroalgae Ascophyllum nodosum and Fucus spp., and collections were taken from mid-intertidal elevations (along approximately 20 to $40 \mathrm{~m}$ of shore).

Forty adult Littorina obtusata snails within a narrow range of shell breadths (8 to $12 \mathrm{~mm}$ ) were sampled from each shore, such that the

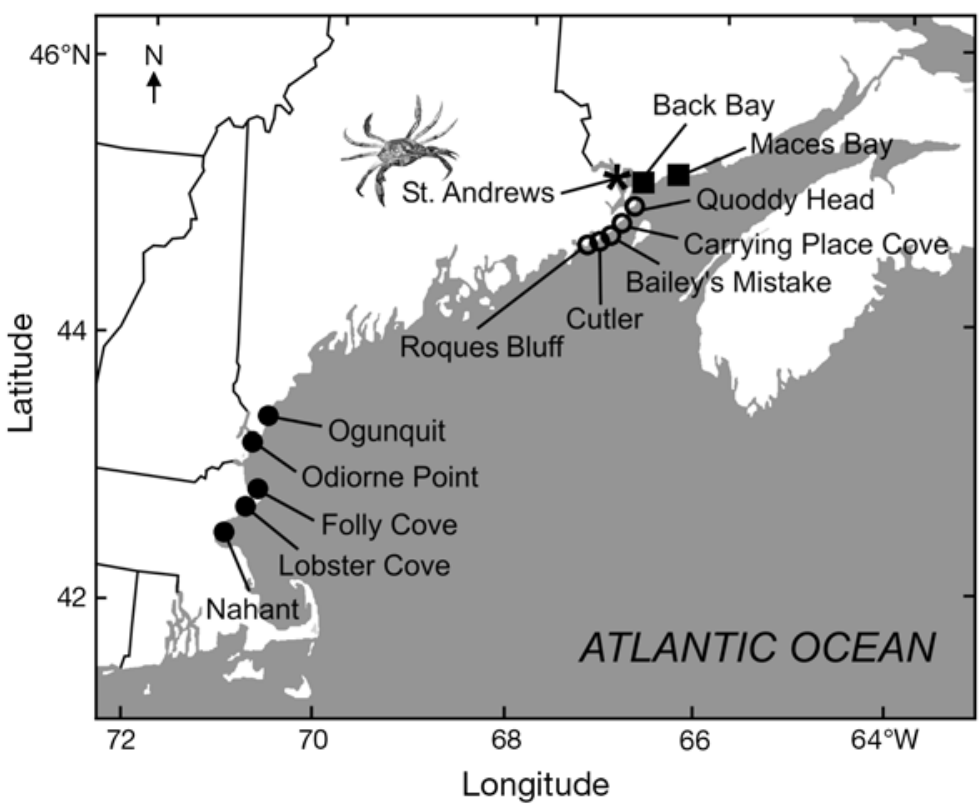

Fig. 2. Geographic survey study sites. Symbols correspond by region to those in Fig. 3: (๑) South Gulf of Maine, (O) north Gulf of Maine, (ロ) Bay of Fundy, (*) Carcinus maenas collection site

first 40 snails found within this range were kept for analysis. Retraction depth was measured and marked on the shells within $12 \mathrm{~h}$ of each field collection. Shell mass, aperture area and angular retraction were measured later in the lab. Importantly, angular retraction measurements were based on the withdrawal depth of snails that was marked within $12 \mathrm{~h}$ of collection from the wild.

Correlation analysis tested for among-population covariance between size-adjusted shell mass and each of the 3 anti-entry traits: aperture area, retraction and angular retraction. Trait values were adjusted for shell size variation by calculating residuals from pooled shell breadth by trait value regressions. In using this approach, we assumed that residual trait values vary with

Table 1. Littorina obtusata and Carcinus maenas. Site coordinates and population densities of L. obtusata snails and C. maenas green crabs used in this study. L. obtusata densities were determined by 10 randomly placed quadrats at midshore (mean $\pm \mathrm{SD})$. C. maenas catch per effort was estimated by flipping rocks during low tide for $60 \mathrm{~min}$

\begin{tabular}{|c|c|c|c|c|}
\hline Site & $\begin{array}{l}\text { Latitude } \\
\qquad(\mathrm{N})\end{array}$ & $\begin{array}{l}\text { Longitude } \\
\text { (W) }\end{array}$ & $\begin{array}{c}\text { No. } \\
\text { L. obtusata } \\
0.25 \mathrm{~m}^{-2}\end{array}$ & $\begin{array}{l}\text { C. maenas } \\
\text { catch h}^{-1}\end{array}$ \\
\hline Maces Bay, NB ${ }^{\mathrm{a}, \mathrm{b}}$ & $45^{\circ} 06.178^{\prime}$ & $66^{\circ} 28.594^{\prime}$ & $46.5 \pm 23.2$ & 119 \\
\hline Back Bay, NB ${ }^{a, b}$ & $45^{\circ} 02.377^{\prime}$ & $66^{\circ} 53.423^{\prime}$ & $13.5 \pm 5.8$ & 123 \\
\hline St. Andrews, NB ${ }^{\mathrm{c}}$ & $45^{\circ} 04.137^{\prime}$ & $67^{\circ} 02.356^{\prime}$ & $2.1 \pm 2.3$ & 122 \\
\hline Quoddy Head, ME ${ }^{\mathrm{a}, \mathrm{b}}$ & $44^{\circ} 48.829^{\prime}$ & $66^{\circ} 57.061^{\prime}$ & $12.4 \pm 5.0$ & 22 \\
\hline $\begin{array}{l}\text { Carrying Place } \\
\text { Cove, } \mathrm{ME}^{\mathrm{a}, \mathrm{b}}\end{array}$ & $44^{\circ} 48.567^{\prime}$ & $66^{\circ} 58.661^{\prime}$ & $25.9 \pm 9.3$ & 56 \\
\hline Bailey's Mistake, $\mathrm{ME}^{\mathrm{a}}$ & $44^{\circ} 46.466^{\prime}$ & $67^{\circ} 03.327^{\prime}$ & $2.2 \pm 1.7$ & 126 \\
\hline Cutler, $\mathrm{ME}^{\mathrm{a}}$ & $44^{\circ} 39.270^{\prime}$ & $67^{\circ} 12.430^{\prime}$ & $3.8 \pm 4.5$ & 56 \\
\hline Roques Bluff, $\mathrm{ME}^{\mathrm{a}}$ & $44^{\circ} 36.489^{\prime}$ & $67^{\circ} 28.601^{\prime}$ & $10.0 \pm 3.3$ & 67 \\
\hline Ogunquit, $\mathrm{ME}^{\mathrm{a}, \mathrm{b}}$ & $43^{\circ} 12.290^{\prime}$ & $70^{\circ} 35.426^{\prime}$ & $9.3 \pm 5.5$ & 66 \\
\hline Odiorne Point, $\mathrm{NH}^{\mathrm{a}}$ & $43^{\circ} 02.396^{\prime}$ & $70^{\circ} 42.898^{\prime}$ & $10.4 \pm 9.2$ & 35 \\
\hline Folly Cove, $\mathrm{MA}^{\mathrm{a}, \mathrm{b}}$ & $42^{\circ} 41.102^{\prime}$ & $70^{\circ} 38.502^{\prime}$ & $13.3 \pm 7.9$ & 37 \\
\hline Lobster Cove, $\mathrm{MA}^{\mathrm{a}}$ & $42^{\circ} 33.846^{\prime}$ & $70^{\circ} 46.207^{\prime}$ & $6.3 \pm 4.5$ & 26 \\
\hline Nahant, $\mathrm{MA}^{\mathrm{a}}$ & $42^{\circ} 25.687^{\prime}$ & $70^{\circ} 55.721^{\prime}$ & $18.4 \pm 8.9$ & 41 \\
\hline
\end{tabular}

shell size similarly in all populations, although this was not always true (ANCOVA shell breadth $\times$ population origin effects, all $\mathrm{p}<0.001$, data not shown). The fact that traits vary with shell size differently among populations suggests that correlations (between traits) may give different results depending on the size of shells considered. Therefore, we prudently conducted additional correlations using trait values predicted for small (8 mm), medium (10 mm) and large (12 mm) shell breadths (per population, using population-specific regressions; $\mathrm{n}=40$ per population, shell breadth range 8 to $12 \mathrm{~mm}$ ) in lieu of the population-mean residual trait values, described above. Main inferences were consistent using either approach.

Predation experiments. To test if natural variability in snail trait values had functional significance, we simultaneously conducted 2 predation experiments: one involving unmanipulated snails from 5 different populations, and 
the other involving snails from a sixth population, in which some had their shell modified to help identify the causes of population differences in mortality. In both experiments snails were fed directly to Carcinus maenas green crabs in the lab (mean crab body size, carapace width $\pm \mathrm{SD}=34.5 \pm 3.3 \mathrm{~mm}$ ). We purposely pitted relatively large Littorina obtusata snails (shell breadth = 9.5 to $11.5 \mathrm{~mm}$ ) against relatively small green crabs to maximize the probability of shell-entry attacks; the positive effect of greater shell thickness on resisting shellcrushing attacks is generally known and accepted, whereas there is no empirical evidence for a relationship between variability in anti-entry traits and differences in defense against shell-entry predation. All green crabs were collected from St. Andrews, Canada (Table 1, Fig. 2) and starved for $5 \mathrm{~d}$ prior to experiment. Experiments were conducted in a climate-controlled facility with recirculating seawater (temperature $=12$ to $14^{\circ} \mathrm{C}$; salinity $=$ $34 \%$ ) at the University of New Brunswick, Saint John.

Snails for the first predation experiment were from 5 of the 12 sites used in the geographic survey (see Table 1), which were selected to maximize amongpopulation variability in traits. Shell mass, aperture area, retraction and angular retraction were estimated in a subsample $(\mathrm{n}=24)$ of each experimental population within $24 \mathrm{~h}$ prior to initiation of the experiment. Snails were caged with crabs for $7 \mathrm{~d}$ (cage dimensions $=12 \times 12 \times 10 \mathrm{~cm})$. Each cage $(\mathrm{n}=90)$ contained 1 green crab and 7 randomly selected snails from a single population. Snail mortality was estimated for each population as the mean number of killed snails among 18 cages ( 9 with male crabs plus 9 with female crabs population ${ }^{-1} ; 18$ cages $\times 5$ populations $=90$ cages .

Snail fate was categorized by shell condition post mortem. Shell-crushing predation occurred when shells were crushed outright or peeled sufficiently to expose the retracted snail prior to its demise (i.e. peeled more than $1 / 4$ turn of the shell body whorl). Shell-entry predation occurred when a snail's soft tissues were partially or completely extracted from its shell, with little or no damage to the shell itself. Sometimes shells suffered minor damage prior to the extraction of flesh, but if the amount of shell breakage was judged to not significantly expose snail flesh to the predator (i.e. peeled less than $1 / 4$ turn of the shell body whorl), then these events were pooled with shell entry.

Snails for the second experiment were from a single site (Back Bay, BB), which was chosen for the snail's fairly pronounced retraction ability. The purpose of this second experiment was to control for confounding variables that may contribute to population-level differences in mortality (other than differences in the trait values of interest, e.g. palatability to green crabs). To do this, we artificially manipulated (reduced) retraction depth and, incidentally, shell mass and aperture area in
BB snails by cutting away $30^{\circ}$ and $60^{\circ}$ of shell from the lip-margin using a hand-held rotary blade (see Fig. 1C). Shells to be cut were collected larger than uncut counterparts, so that after cutting all shells would be similar in size. This manipulation effectively changed angular retraction by the prescribed amounts: $\mathrm{BB}$ (wild), $\mathrm{BB}$ $\left(-30^{\circ}\right)$ and BB $\left(-60^{\circ}\right)$. There were 10 cages of each condition, with a single male crab and 7 snails per cage (cage dimensions and animal size as in first experiment). Mortality estimates were made after $7 \mathrm{~d}$.

Correlation analyses tested for relationships between mean population mortality and mean population trait values. We assumed that green crabs would crush shells outright when possible, i.e. thin and/or small shells are invariably crushed by green crabs (Rochette et al. 2007, Edgell \& Neufeld 2008), and shell crushing is likely the preferred tactic, yielding $100 \%$ of available flesh per prey item. In contrast, extraction typically gives a crab only a fraction of available flesh, because the snail tissue often tears during extraction, leaving behind tissues in the deepest whorls of the snail's shell. Therefore, it was necessary to quantify the proportion of kills by shell entry relative to the non-crushable portion of the population. Without transformation, a population that may suffer $100 \%$ shell-crushing predation would appear to be $100 \%$ efficient at defending against shell-entry predation. Therefore, the rate of mortality by shell crushing was analyzed simply as \% crushed, whereas the rate of mortality by shell-entry attacks was calculated as the number of kills by shell entry divided by the value equal to the total number of snails at time $=$ 0 minus the number of kills by shell crushing. Additionally, because both male and female green crabs were used in the first predation experiment but only males were used in the second, we performed regression analyses twice: first, by including all replicate cages and second, by using only male green crab replicate cages. This redundant analysis was necessary to prevent potential biases introduced by sex-specific differences in predation. Finally, because BB (wild) snails were never in contact with the rotary blade, there is a potential 'cutting artifact' on survivorship that cannot be accounted for in comparisons between manipulated and unmanipulated shells. However, both BB $\left(-30^{\circ}\right)$ and $\mathrm{BB}\left(-60^{\circ}\right)$ are directly comparable in terms of this potential artifact, which enables assessment of its effect (using a 1-tailed $t$-test), relative to that of withdrawal distance, on snail survivorship.

\section{RESULTS}

Among-population $(n=12)$ differences in shell mass and aperture area were inversely related $(\mathrm{R}=0.75, \mathrm{p}=$ 0.005), whereas mass and retraction $(R=0.76, p=$ 
$0.005)$ and mass and angular retraction $(\mathrm{R}=0.74, \mathrm{p}=$ 0.006) were positively related (Fig. 3). These relationships are based on residual mean trait values, and thus standardized for shell breadth (see 'Materials and methods'). These results were largely consistent with those of an alternative approach, which tested for correlations among sites $(n=12)$ using trait estimates for small, medium, and large shell breadths. Shell mass was negatively correlated with aperture area (shell

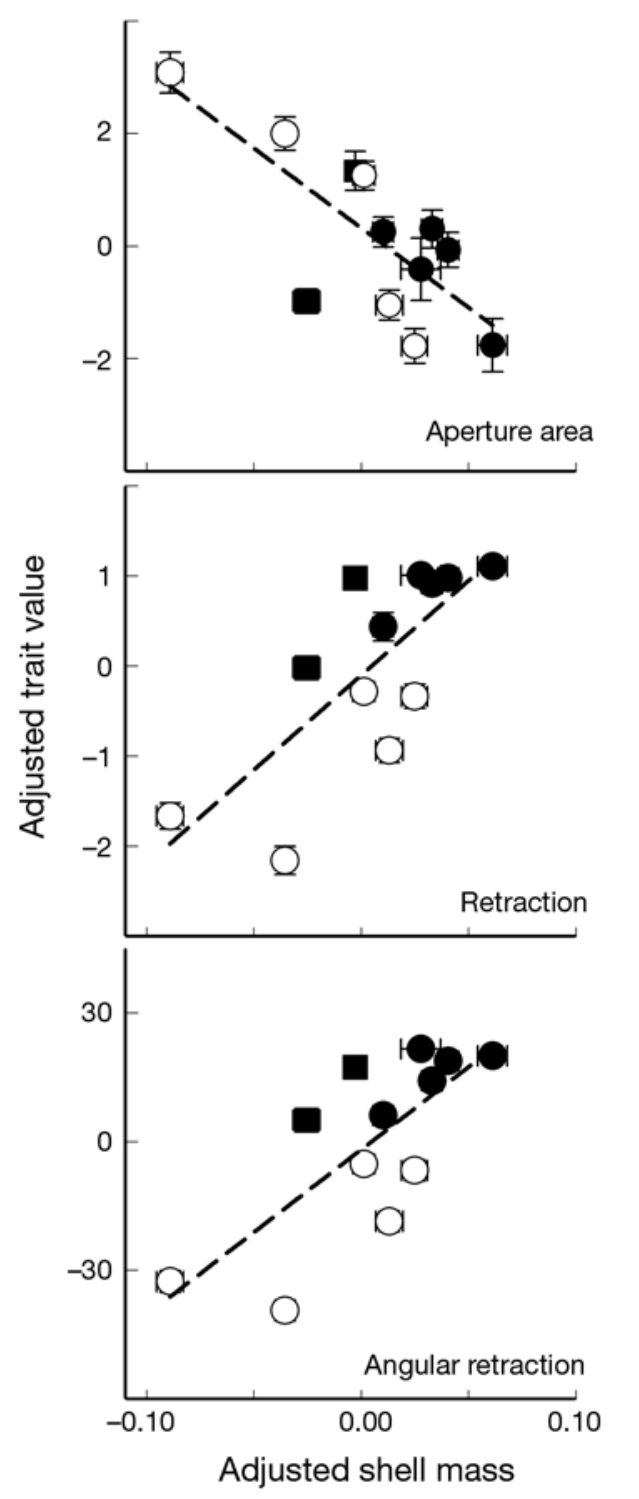

Fig. 3. Littorina obtusata. Relationship between size-adjusted shell mass and shell aperture area $(R=0.75, p=0.005)$, soft tissue retraction $(\mathrm{R}=0.76, \mathrm{p}=0.005)$, and soft tissue angular retraction ( $R=0.74, p=0.006$ ) for 12 L. obtusata populations (each point is the mean $\pm \mathrm{SE}$ of 40 snails per population) in the north Gulf of Maine (O), south Gulf of Maine (৩), and Bay of Fundy (ם). All values have been adjusted for variation due to shell size (see 'Materials and methods'). Shell breadth ranges from 8 to $12 \mathrm{~mm}$ breadth: $8 \mathrm{~mm}, \mathrm{R}=0.07, \mathrm{p}=0.83 ; 10 \mathrm{~mm}, \mathrm{R}=0.69, \mathrm{p}=$ $0.014 ; 12 \mathrm{~mm}, \mathrm{R}=0.83, \mathrm{p}=0.0008$ ); in contrast, shell mass was positively correlated with retraction $(8 \mathrm{~mm}$, $\mathrm{R}=0.81, \mathrm{p}=0.0016 ; 10 \mathrm{~mm}, \mathrm{R}=0.57, \mathrm{p}=0.0044 ;$ $12 \mathrm{~mm}, \mathrm{R}=0.66, \mathrm{p}=0.019$ ), as was shell mass with angular retraction $(8 \mathrm{~mm}, \mathrm{R}=0.67, \mathrm{p}=0.015 ; 10 \mathrm{~mm}$, $\mathrm{R}=0.73, \mathrm{p}=0.0066 ; 12 \mathrm{~mm}, \mathrm{R}=0.71, \mathrm{p}=0.0095)$.

Combined results of predation Expts 1 and 2 showed that $42 \%$ of snails were killed. Of those killed, $12 \%$ died by shell crushing versus $88 \%$ by shell entry (32\% of those killed by extraction had minor damage to their shells; see 'Materials and methods'). Mortality rates varied markedly among populations ( $\mathrm{n}=8$, Expts 1 and 2 combined) (Fig. 3), and mean mortality was correlated to interpopulation differences in anti-crushing and anti-entry trait values. The frequency of deaths by shell crushing was generally lower in populations with more massive shells, as the 5 most massive populations experienced no mortalities via this mode of attack (male and female predators combined: $\mathrm{R}=0.72, \mathrm{p}=$ 0.046; male predators only: $\mathrm{R}=0.68, \mathrm{p}=0.061$ ) (Fig. 4a). The frequency of deaths by shell entry was lower in populations with (1) smaller shell openings (apertures) (male and female predators: $\mathrm{R}=0.75, \mathrm{p}=$ 0.0336; male predators: $\mathrm{R}=0.79, \mathrm{p}=0.0209$ ); (2) deeper retraction depths (male and female predators: $\mathrm{R}=0.92$, $\mathrm{p}=0.0015$; male predators: $\mathrm{R}=0.89, \mathrm{p}=0.0027$ ); and (3) larger angular retraction depths (male and female predators: $\mathrm{R}=0.94, \mathrm{p}=0.0006$; male predators: $\mathrm{R}=$ 0.94, $\mathrm{p}=0.0006$ ) (Fig. $4 \mathrm{~b}-\mathrm{d})$. Mortality for BB $\left(-30^{\circ}\right)$ snails was significantly less than for BB $\left(-60^{\circ}\right)$ snails $\left(t_{0.05(1), 18}=1.82, \mathrm{p}=0.043\right)$ (Fig. $\left.4 \mathrm{~b}-\mathrm{d}\right)$.

\section{DISCUSSION}

Marine mollusks in the fossil record show a proliferation of anti-crushing traits over the past several million years, met collaterally with a diversification of shell-crushing predators (Vermeij 1987). This escalation of antagonistic characteristics indicates the importance of shell-crushing predation to the evolution of mollusks and molluscivores, and it may thus come as no surprise that some descendents of these molluscivores, like the European green crab Carcinus maenas, have evolved behavioural flexibility to counter the effectiveness of anti-crushing traits.

European green crabs are indeed versatile predators, and they exhibit a high degree of behavioural flexibility when preying on Littorina obtusata snails in particular. Snails with shells that are small or lightweight (i.e. those that are easy to break) are broken. Snails with shells that are big or massive (i.e. those that are tough to break) have their flesh extracted from through the shell opening (Rochette et al. 2007). Dur- 

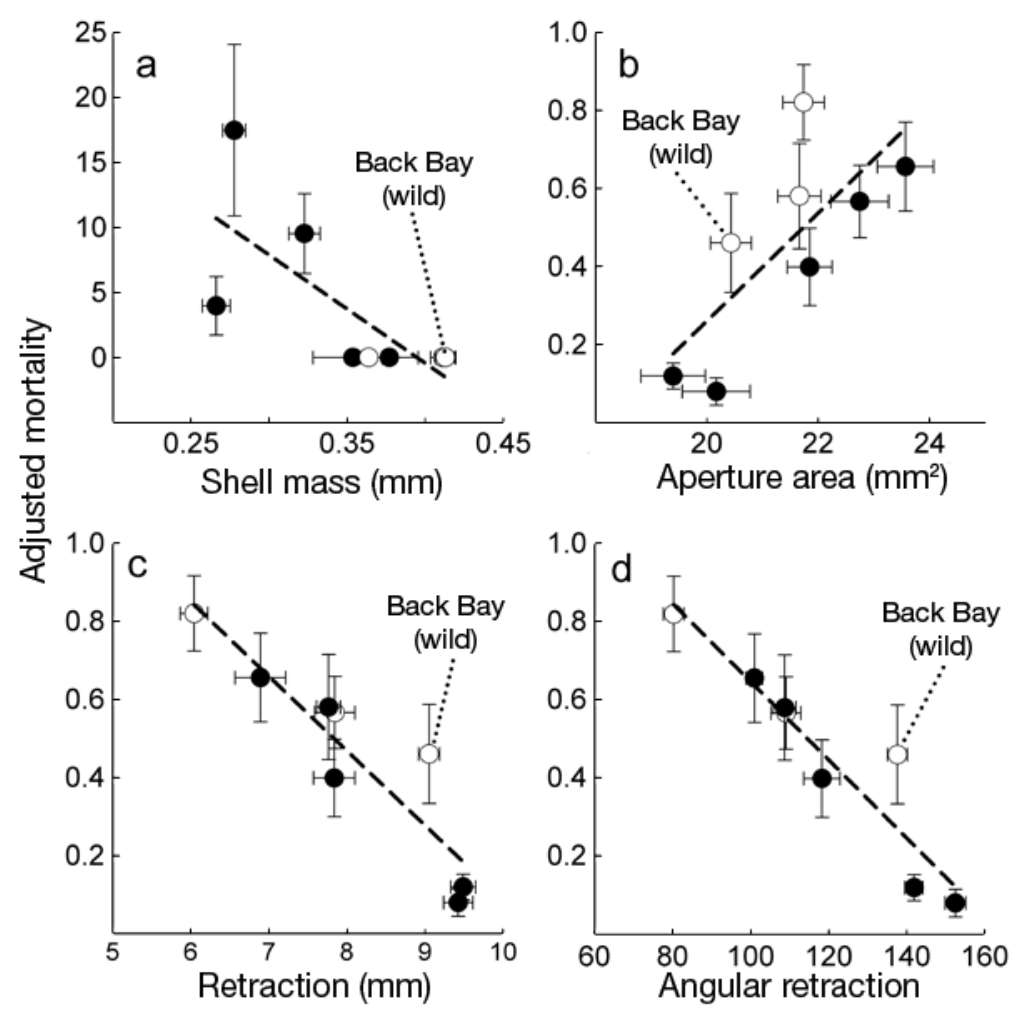

Fig. 4. Littorina obtusata. Relationship between shell character and mortality of L. obtusata snails from 6 natural and 2 manipulated populations during the laboratory predation experiment. O: 3 Back Bay 'populations', 1 wild type and 2 that were physically modified to adjust retraction depth, and incidentally shell mass and aperture area; each point represents the mean $( \pm \mathrm{SE})$ of 24 snails population ${ }^{-1}$. Mortality estimates: (a) \% of kills by shell-crushing, or $(\mathrm{b}-\mathrm{d})$ proportion of kills by shell-entry relative to the non-crushable portion of the population (see 'Materials and methods')

ing this latter mode of attack, green crabs effectively overcome the snail's anti-crushing defenses. However, an exceptionally large green crab (e.g. carapace width $=70$ to $90 \mathrm{~mm}$, larger than those used in our predation experiment), or at least one with a particularly large crushing claw, will unquestionably destroy L. obtusata's shell upon attack. The opposite is true for small green crabs, or at least those with relatively small claws, which are forced to rely on shell-entry attacks when preying on L. obtusata with only moderately large or thick shells. For instance, experimental work shows that the frequency of snails killed by shell entry increases with shell size, whereas the frequency of snail kills by shell crushing gradually decreases (Rochette et al. 2007). The fact that green crab feeding behaviour appears to change as a function of snail size indicates behavioural flexibility, or plasticity. Ultimately, this switch between behaviours, depending on the relative magnitude of prey defense, suggests that neither anti-shell-crushing nor anti-shell-entry defenses alone are likely to protect snails when green crabs are a dominant predator.

In the northwest Atlantic, shell mass (a good predictor of crushing resistance; Lowell et al. 1994) of Littorina obtusata snails co-varies among populations with the size of crusher claws in sympatric green crabs (Edgell \& Rochette 2007, 2008); thus shell-crushing appears important to the interaction of these species in the wild. We report that anti-entry traits also co-vary with snail shell mass among populations (Fig. 3); thus in areas where snails are better defended against shellcrushing predation they also appear to be better defended against shell-entry predation. The adaptive significance of this natural variability was clearly demonstrated during predation experiments in the lab (present study), where populations with relatively lightweight shells, large apertures and shallow withdrawal depths had the greatest rates of mortality when attacked by green crabs (Fig. 4). We are confident that the interpopulation differences in mortality in the lab were due to variability in the expression of morphological traits under study (as opposed to another confounding variable like interpopulation differences in palatability to green crabs), because artificially modified withdrawal depths from singleorigin snails followed the same general trends: of the 2 manipulated BB populations, that with deeper withdrawal depth had significantly greater survivorship than that with shallower withdrawal (Fig. 4b-d). Incidentally, no snails from this artificially modified population were killed by shell crushing; thus we were unable to test for confounding variables contributing to interpopulation differences in shell-crushing mortality. Nonetheless, the relationship between shell mass (or thickness) and resistance to shell-crushing predation by green crabs has already been documented for L. obtusata (Rochette et al. 2007, Edgell \& Rochette 2008) and other gastropods (Edgell \& Neufeld 2008).

The generality of these laboratory results is perhaps questionable given they were generated using a single green crab population; thus any putative genetic or epigenetic characters that are unique to the St. Andrews green crab population may preclude the applicability of these lab results elsewhere. However, both shell-crushing and shell-entry predation by this species has been identified independently by researchers in Canada, the USA, Ireland and Sweden 
(Ebling et al. 1964, Hadlock 1980, Johannesson 1986, Rochette et al. 2007, Edgell \& Rochette 2008), suggesting that such a duality of predation behaviours is likely widespread. Although both modes of predation may be common, geographic differences in the preponderance of one tactic over the other is probable, given some green crab populations appear to be better at shell-crushing than others (Smith 2004, Edgell \& Rochette 2007, 2008). However, although such variability in shell-crushing or shell-entry success among shores should cause the absolute proportions of kills by crushing or kills by shell entry to change, there is no reason to believe that the relationship between shell mass and survivorship, or withdrawal depth and survivorship, should differ. When green crabs (or other shell-crushing predators) intend to break shells, those snails with the most massive shells will have a survivorship advantage; when green crabs (or other shell-entering predators) attempt to extract snail flesh, those snails with deeper withdrawal depth will more likely survive.

Admittedly, we have little understanding of the modularity of anti-breaking and anti-entry traits. Can they vary independently of each other if snails are faced primarily with one kind of predation pressure? Or, are they developmentally linked (via developmental constraints or pleiotropy)? For example, when standardized for shell breadth, the more massive of 2 hypothetical shells will also have a smaller aperture (assuming similar shell shapes; Brookes \& Rochette 2007); thus the geographic covariance between shell mass and shell aperture smallness (Fig. 3) may be an artifact of correlated characters and not a simultaneous response to both shell-crushing and shell-entry predation pressures. It is less clear how the relationship between shell mass and soft tissue withdrawal depth could be due to such a developmental constraint. In other words, why would shell mass and withdrawal depth co-vary if not because of a concurrent response to shell-crushing and shell-entry predation? Theoretically, from a correlated development perspective, we may expect the opposite: as shell mass increases and shell openings get smaller, we would also expect internal shell volume to decrease and thus soft tissue withdrawal would presumably become more difficult (i.e. physically constrained). Research is needed to elucidate the developmental interdependence of these different anti-predation traits.

We suggest that shell-entry predation is perhaps more important to crab-snail coevolution than previously thought. In the present study, with the interaction between Carcinus maenas green crabs and Littorina obtusata snails, we provide compelling evidence that aperture occlusion and soft tissue withdrawal depth are indeed adaptive defenses against shell- entering green crabs. Furthermore, results suggest that the combination of shell-entry and shell-crushing predation by green crabs has structured the overall defensive phenotype of $L$. obtusata along the New England coast: where snails are well defended against shell-entry, they are also well defended against shellcrushing.

A potentially fruitful avenue for future research pertains to the mechanisms that underlie variation in these defensive traits. Possibilities include evolution by natural selection, whereby anti-crushing and antientry traits are under genetic control and thus selection for either (or both) preserves their expression in predator-rich environments. Incidentally, if these traits are genetically linked (e.g. pleiotropy) then selection for one, say shell strength, may ensure expression of the other, deep withdrawal depth. Another possible mechanism would entail shell mass and withdrawal depth to be developmentally plastic, inducible by water-borne, predator risk cues (Appleton \& Palmer 1988). For example, Littorina obtusata snails respond to the effluent from feeding green crabs by developing thicker shells and smaller apertures (Trussell \& Smith 2000, Trussell \& Nicklin 2002, Brookes \& Rochette 2007 ); the inducible effect of green crab scent on snail withdrawal depth requires further study. Therefore, if predation intensity varies regionally, then phenotypic plasticity could explain the correlated expression of anti-breaking and anti-entry defensive traits among populations of L. obtusata. A third possibility, perhaps in better alignment with modern paradigms of evolutionary theory (Schlichting \& Pigliucci 1998, WestEberhard 2005), is that natural selection is operating on trait plasticity itself, whereby snail populations having experienced more historical variability in green crab predation risk are expected to evolve greater developmental plasticity (Hollander 2008). In this latter scenario, population-level differences in traits would therefore be both genetically and environmentally mediated, in which case a comparison of developmental reaction norms among snail populations experiencing different levels of crab predation would be enlightening. Finally, we suggest that biological invasions are a particularly relevant approach to study prey adaptation, insomuch that new and intense interactions that develop after introduction are likely to be followed by rapid diversifications in form as species respond to their new enemies.

Acknowledgements. Thanks to M. Drolet and S. Currie for lab and field support. We are grateful to E. G. Boulding, S. B. Heard, J. Houlahan, S. P. Doyle, and 3 anonymous reviewers for critical review of the manuscript. Funded by a NSERC Discovery Grant (249966-02), a CFI New Opportunities Grant (6026) and a NBIF Research Innovation Grant to R.R., and a UNB Graduate Research Assistantship to T.C.E. 


\section{LITERATURE CITED}

Appleton RD, Palmer AR (1988) Water-borne stimuli released by predatory crabs and damaged prey induce more predator-resistant shells in a marine gastropod. Proc Natl Acad Sci USA 85:4387-4391

Brookes JI, Rochette R (2007) Mechanism of a plastic phenotypic response: predator-induced shell thickening in the intertidal gastropod Littorina obtusata. J Evol Biol 20: 1015-1027

Cunningham PN, Hughes RN (1984) Learning of predatory skills by shorecrabs Carcinus maenas feeding on mussels and dogwhelks. Mar Ecol Prog Ser 16:21-26

DeWitt TJ, Langerhans RB (2003) Multiple prey traits, multiple predators: keys to understanding complex community dynamics. J Sea Res 49:143-155

DeWitt TJ, Robinson BW, Wilson DS (2000) Functional diversity among predators of a freshwater snail imposes an adaptive trade-off for shell morphology. Evol Ecol Res 2:129-148

Ebling FJ, Kitching JA, Muntz L, Taylor CM (1964) The ecology of Lough Ine: XIII. Experimental observations of the destruction of Mytilus edulis and Nucella lapillus by crabs. J Anim Ecol 33:73-82

Edgell TC, Neufeld CJ (2008) Experimental evidence for latent developmental plasticity: intertidal whelks respond to a native but not an introduced predator. Biol Lett 4: 385-387

Edgell TC, Rochette R (2007) Geographic correlation between reciprocally-adaptive traits of an exotic decapod predator and native gastropod prey: Evidence of an arms race? Evol Ecol Res 9:579-597

Edgell TC, Rochette R (2008) Differential snail predation by an exotic crab and the geography of shell-claw covariance in the northwest Atlantic. Evolution 62:1216-1228

Elner RW, Hughes RN (1978) Energy maximization in the diet of the shore crab, Carcinus maenas. J Anim Ecol 47: 103-116

Hadlock RP (1980) Alarm response of the intertidal snail Littorina littorea (L.) to predation by the crab Carcinus

Editorial responsibility: Roger Hughes,

Bangor, UK maenas (L.). Biol Bull 159:269-279

- Hollander J (2008) Testing the grain-size model for the evolution of phenotypic plasticity. Evolution 62:1381-1389

> Johannesson B (1986) Shell morphology of Littorina saxatilis Olivi: the relative importance of physical factors and predation. J Exp Mar Biol Ecol 102:183-195

Lowell RB, Fletcher CR, Grahame J, Mill PJ (1994) Ontogeny of shell morphology and shell strength of the marine snails Littorina obtusata and Littorina mariae: different defense strategies in a pair of sympatric, sibling species. J Zool Lond 234:149-164

Rochette R, Doyle SP, Edgell TC (2007) Interaction between an invasive decapod and a native gastropod: predator foraging tactics and prey architectural defenses. Mar Ecol Prog Ser 330:179-188

Schlichting CD, Pigliucci M (1998) Phenotypic evolution: a reaction norm perspective. Sinauer Associates, Sunderland, MA

Seeley RH (1986) Intense natural selection caused a rapid morphological transition in a living marine snail. Proc Natl Acad Sci USA 83:6897-6901

Smith LD (2004) Biogeographic differences in claw size and performance in an introduced crab predator Carcinus maenas. Mar Ecol Prog Ser 276:209-222

Trussell GC (1996) Phenotypic plasticity in an intertidal snail: the role of a common crab predator. Evolution 50:448-454

Trussell GC, Nicklin MO (2002) Cue sensitivity, inducible defense, and trade-offs in a marine snail. Ecology 83: 1635-1647

Trussell GC, Smith LD (2000) Induced defenses in response to an invading crab predator: an explanation of historical and geographic phenotypic change. Proc Natl Acad Sci USA 97:2123-2127

Vermeij GJ (1982) Phenotypic evolution in a poorly dispersing snail after arrival of a predator. Nature 299:349-350

Vermeij GJ (1987) Evolution and escalation: an ecological history of life. Princeton University Press, Princeton, NJ

West-Eberhard MJ (2005) Developmental plasticity and the origin of species differences. Proc Natl Acad Sci USA 102:6543-6549

Submitted: May 15, 2008; Accepted: August 14, 2008 Proofs received from author(s): October 15, 2008 